\title{
Defunctioning Stomas Result in Significantly More Short-Term Complications Following Low Anterior Resection for Rectal Cancer
}

\author{
Andrew Emmanuel ${ }^{1}$ (D) Ezzat Chohda ${ }^{1} \cdot$ Christo Lapa $^{1} \cdot$ Andrew Miles $^{2} \cdot$ \\ Amyn Haji ${ }^{1} \cdot$ Joe Ellul $^{1}$
}

Published online: 17 May 2018

(C) The Author(s) 2018

\begin{abstract}
Background Studies suggest that defunctioning stomas reduce the rate of anastomotic leakage and urgent reoperations after anterior resection. Although the magnitude of benefit appears to be limited, there has been a trend in recent years towards routinely creating defunctioning stomas. However, little is known about post-operative complication rates in patients with and without a defunctioning stoma. We compared overall short-term post-operative complications after low anterior resection in patients managed with a defunctioning stoma to those managed without a stoma.

Methods A retrospective cohort study of patients undergoing elective low anterior resection of the rectum for rectal cancer. The primary outcome was overall 90-day post-operative complications.

Results Two hundred and three patients met the inclusion criteria for low anterior resection. One hundred and forty $(69 \%)$ had a primary defunctioning stoma created. $45 \%$ received neoadjuvant radiotherapy. Patients with a defunctioning stoma had significantly more complications ( 57.1 vs $34.9 \%, p=0.003$ ), were more likely to suffer multiple complications $(17.9$ vs $3.2 \%, p<0.004)$ and had longer hospital stays $(13.0$ vs 6.9 days, $p=0.005)$ than those without a stoma. $19 \%$ experienced a stoma-related complication, $56 \%$ still had a stoma 1 year after their surgery, and $26 \%$ were left with a stoma at their last follow-up. Anastomotic leak rates were similar but there was a significantly higher reoperation rate among patients managed without a defunctioning stoma.

Conclusion Patients selected to have a defunctioning stoma had an absolute increase of $22 \%$ in overall post-operative complications compared to those managed without a stoma. These findings support the more selective use of defunctioning stomas.

Study registration Registered at www.researchregistry.com (UIN: researchregistry3412).
\end{abstract}

Andrew Emmanuel

aemmanuel@nhs.net

Ezzat Chohda

e.chohda@nhs.net

Christo Lapa

christolapa@nhs.net

Andrew Miles

milesajg@ doctors.org.uk

Amyn Haji

amynhaji@nhs.net
Joe Ellul

joe.ellul@nhs.net

1 Department of Colorectal Surgery, King's College Hospital NHS Foundation Trust, London, UK

2 Department of Colorectal Surgery, Hampshire Hospitals NHS Foundation Trust, Wessex, UK 


\section{Introduction}

The routine use of defunctioning stomas during anterior resection has increased in recent years with several national audits and colorectal cancer registries demonstrating approximately $80 \%$ or more of patients undergoing anterior resection for rectal cancer are managed with defunctioning stomas [1-3]. Several studies suggest that patients who have a defunctioning stoma created during anterior resection have a lower risk of anastomotic leak, or a lower risk of requiring urgent reoperation, than patients who do not have a defunctioning stoma [4-7]. However, the quality of many of these studies is poor, the magnitude of this benefit is uncertain and it is not clear which patients may benefit most from a defunctioning stoma. Overall post-operative complications are rarely reported in these studies. There are very few studies specifically comparing the overall complications in patients managed with and without defunctioning stomas [8-10] and these generally involve small numbers of patients and report conflicting results. Despite the paucity of comparative studies, a number of case series suggest that there is significant short-term morbidity associated with defunctioning stomas [11-13].

Given that the majority of the large proportion of patients who are managed with a defunctioning stoma will not derive any benefit from it, it is important to understand if creating a stoma, which is a significant additional procedure in an already long and complex operation, is associated with an increase in overall complications. If patients with a defunctioning stoma have a clinically significant increase in overall complications compared to those who do not have a stoma, this may influence surgeons' decisions regarding the benefit of defunctioning stomas during anterior resection and may lead to more selective use of stomas.

The aim of this study is to determine if patients who receive a defunctioning stoma during elective low anterior resection of the rectum for rectal cancer have a clinically significant increase in overall post-operative complications compared to patients who do not receive a defunctioning stoma.

\section{Materials and methods}

\section{Study design and outcomes}

This is a retrospective cohort study of consecutive patients with rectal cancer treated by elective low anterior resection of the rectum at a single hospital trust comprising two hospitals between 1st January 2009 and 31st December 2014. All procedures were performed or directly supervised by colorectal surgeons trained in TME. The procedures adhered to the principles of total mesorectal excision or tumour-specific modified mesorectal excision depending on the level of the tumour. In general, total mesorectal excision is performed for all middle and lower rectal cancers while modified tumour-specific mesorectal excision can be used for upper rectal cancers, with the mesorectum divided no less than $5 \mathrm{~cm}$ below the margin of the tumour [14]. Defunctioning stomas were created at the discretion of the operating surgeon. Perioperative management was based on an enhanced recovery after surgery protocol including essential principles as per ERAS society guidelines, including pre-operative counselling and education, medical optimisation, no overnight fasting, preoperative carbohydrate loading drinks, standard management for premedication, analgesia and post-operative nausea and vomiting, venous thromboembolism prophylaxis, antibiotic prophylaxis, avoidance of nasogastric tubes and abdominal drains, early post-operative diet and early mobilisation [15]. Sample size calculation was performed based on detecting a clinically significant increase in the overall complication rate of $20 \%$ from 25 to $45 \%$ (RR 1.8) with a power 0.8 and alpha 0.05 , assuming that $65 \%$ of patients would have a defunctioning stoma created at anterior resection. An increase in the complication rate of $20 \%$ was chosen as an increase in a magnitude significant enough to influence a surgeon's decision regarding whether to routinely form a defunctioning stoma. The calculation yielded a necessary sample size of 197 patients (128 with a defunctioning stoma and 69 without).

The primary outcome was the overall post-operative complication rate within 90 days of surgery. Secondary outcomes included length of hospital stay, readmission, reoperation, multiple complications, mortality and stomarelated complications.

\section{Definition of low anterior resection}

The Tripartite Consensus Conference on Definitions for Anorectal Physiology and Rectal Cancer definition of low anterior resection was used, which is a colorectal resection with anastomosis of the colon to extraperitoneal rectum (anastomosis below the peritoneal reflection) [16]. Although it is difficult to assign an exact level for the anterior peritoneal reflection in each individual, studies in living subjects place it at approximately $9 \mathrm{~cm}$ [17].

\section{Criteria to identify patients with a low anterior resection}

Patients with tumours $12 \mathrm{~cm}$ or less from the anal verge were included as these patients are consistently likely to have a distal resection margin below the peritoneal 
reflection, which is consistent with the tumour height used in other studies of low anterior resection [18-20]. The tumour level was determined by the pre-operative MRI scan as MRI provides an objective, accurate and reproducible means of assessing rectal tumours [21] and documentation of the level of the tumour from the anal verge is now internationally accepted as a reporting standard for pre-operative MRI [22, 23]. If the tumour level was not documented pre-operatively then patients were included if histopathological analysis of the resection specimen clearly showed a distal resection margin below the anterior peritoneal reflection.

\section{Data collection}

Data were collected by exhaustive review of patients' clinical notes, operative record, post-operative follow-up visits and reports of radiological and histopathological findings. Data collected included patient demographics, comorbidities, ASA score, body mass index (BMI), preoperative radiological staging, neoadjuvant therapy, surgical technique, date of stoma reversal, length of hospital stay, outcomes within 90 days of surgery including postoperative complications, mortality and reoperation, and histopathological staging and findings.

Short-term post-operative complications were defined as complications within 90 days of the primary operation and stratified according to the Clavien-Dindo classification [24]. Multiple complications were defined as $\geq 2$ complications of any Clavien-Dindo grade experienced by the same patient. Ileus was defined as non-mechanical bowel obstruction requiring the passage of a nasogastric tube associated with high volume aspirates and bowel obstruction as radiological evidence of bowel obstruction with a transition point. High-output stoma was defined as production of $\geq 2000 \mathrm{ml}$ of effluent per day.

\section{Data analysis}

Comparisons were made between patients who received an initial defunctioning stoma at anterior resection and patients who did not receive a defunctioning stoma. Categorical data were analysed using the $X^{2}$ test. Means of continuous data were analysed using the $t$ test. Multiple logistic regression analysis was used to determine significant differences in characteristics between patients managed with and without a defunctioning stoma.

\section{Ethical approval and study registration}

This study was approved by the National Research Ethics Service (REC reference 15/LO/1630). The study was registered with Research Registry (www.researchregistry. com).

\section{Results}

Two hundred and fifty-nine patients underwent elective anterior resection of the rectum for rectal cancer. Two hundred and four patients met the study criteria for low anterior resection; one was excluded as sections of the clinical notes were missing. Two hundred and three patients were included in the study.

\section{Patient characteristics}

Patient characteristics are shown in Table 1. The mean age of patients was 66.9 years, $65 \%$ were male, $55.7 \%$ had laparoscopic anterior resection and $44.8 \%$ had received neoadjuvant radiotherapy. $69 \%$ of patients received an initial defunctioning stoma.

Table 2 shows the characteristics of patients with a defunctioning stoma compared to those without. On univariate analysis, there were significant differences between patients who had received neoadjuvant radiotherapy, patients who underwent open surgery, tumour level and the operating surgeon. There were otherwise no significant differences for all other characteristics.

Significant differences identified on univariate analysis were further subjected to multiple logistic regression analysis (Table 3). Only the operating surgeon was independently associated with whether a stoma was formed with one surgeon significantly less likely to use a defunctioning stoma. Surgical technique (open surgery) was not a significant factor.

Table 4 compares patient characteristics according to tumour level. Patients with low rectal tumours were more likely to receive neoadjuvant radiotherapy, in keeping with standard practice in the UK.

\section{Outcomes}

The overall 90-day complication rate was $50.2 \%$ and 2 (1\%) patients died within 90 days of surgery.

Patients who had a defunctioning stoma created had significantly more overall complications than those managed without a stoma (57.1 vs $34.9 \%$, OR 2.48 , $p=0.003)$ (Table 5).

Patients managed with a defunctioning stoma were less likely to require reoperation. There were no significant differences between groups in anastomotic leak rates or abdominal sepsis overall (anastomotic leaks, enterotomy or intraabdominal collection not meeting the definition of anastomotic leak), readmissions or mortality. However, 
Table 1 Patient and tumour characteristics

\begin{tabular}{|c|c|}
\hline & $N(\%)$ \\
\hline \multicolumn{2}{|l|}{ Gender } \\
\hline Male & $132(65)$ \\
\hline Female & $71(35)$ \\
\hline Mean age in years (median, range) & $66.9(69,22-88)$ \\
\hline \multicolumn{2}{|l|}{ Charlson comorbidity score } \\
\hline $0-3$ & $162(79.8)$ \\
\hline $4-5$ & $17(8.4)$ \\
\hline $6-7$ & $21(10.3)$ \\
\hline$>8$ & $3(1.5)$ \\
\hline \multicolumn{2}{|l|}{ ASA score } \\
\hline 1 & $54(26.6)$ \\
\hline 2 & $92(45.3)$ \\
\hline 3 & $52(25.6)$ \\
\hline 4 & $5(2.5)$ \\
\hline \multicolumn{2}{|l|}{ Neoadjuvant therapy } \\
\hline Receiving radiotherapy in any regimen & $91(44.8)$ \\
\hline Long course chemoradiotherapy & $78(38.6)$ \\
\hline Radiotherapy only & $13(6.4)$ \\
\hline Chemotherapy only & $16(7.9)$ \\
\hline \multicolumn{2}{|l|}{ Surgical technique } \\
\hline Laparoscopic & $113(55.7)$ \\
\hline Laparoscopic converted to open & $13(6.4)$ \\
\hline Open & $77(37.9)$ \\
\hline Defunctioning stoma & $140(69)$ \\
\hline Loop ileostomy & $93(45.8)$ \\
\hline Loop colostomy & $47(23.2)$ \\
\hline \multicolumn{2}{|l|}{ TNM stage (pathological) } \\
\hline $\mathrm{pCR}$ & $11(5.5)$ \\
\hline No residual tumour after local resection & $3(1.5)$ \\
\hline \multicolumn{2}{|l|}{$T$ stage } \\
\hline$T 1$ & $13(6.5)$ \\
\hline$T 2$ & $39(19.5)$ \\
\hline$T 3$ & $113(56.5)$ \\
\hline$T 4$ & $21(10.5)$ \\
\hline \multicolumn{2}{|l|}{$N$ stage } \\
\hline NO & $126(62.1)$ \\
\hline$N 1$ & $51(25.1)$ \\
\hline$N 2$ & $26(13.8)$ \\
\hline \multicolumn{2}{|l|}{$M$ stage } \\
\hline$M 0$ & $183(90.1)$ \\
\hline$M 1$ & $20(9.9)$ \\
\hline
\end{tabular}

Percentages in parenthesis

$\mathrm{pCR}=$ complete pathological response to neoadjuvant therapy

patients who received a primary stoma were significantly more likely to develop post-operative ileus and to experience multiple complications.
Table 2 Univariate analysis comparing characteristics of patients with a defunctioning stoma to those without

\begin{tabular}{|c|c|c|c|}
\hline \multirow[t]{2}{*}{ Characteristic } & \multicolumn{2}{|c|}{ Defunctioning stoma } & \multirow[t]{2}{*}{$\overline{p \text { value }^{\mathrm{a}}}$} \\
\hline & Yes $n=140$ & No $n=63$ & \\
\hline Male sex & $93(66.4)$ & $39(61.9)$ & 0.53 \\
\hline \multicolumn{4}{|l|}{ ASA score } \\
\hline 1 & $41(29.3)$ & $13(20.6)$ & \multirow{4}{*}{0.18} \\
\hline 2 & $66(47.1)$ & $26(41.3)$ & \\
\hline 3 & $30(21.4)$ & $22(34.9)$ & \\
\hline 4 & $3(2.1)$ & $2(3.1)$ & \\
\hline \multicolumn{4}{|l|}{ Charlson score } \\
\hline $0-3$ & $110(78.6)$ & $52(82.5)$ & \multirow{4}{*}{0.89} \\
\hline $4-5$ & $12(8.6)$ & $5(7.9)$ & \\
\hline $6-7$ & $16(11.4)$ & $5(7.9)$ & \\
\hline$>8$ & $2(1.4)$ & $1(1.6)$ & \\
\hline \multicolumn{4}{|l|}{ Surgical technique } \\
\hline Laparoscopic & $74(52.9)$ & $52(82.5)$ & \multirow[t]{2}{*}{$<0.001$} \\
\hline Open & $66(47.1)$ & $11(17.5)$ & \\
\hline Neoadjuvant radiotherapy & $72(51.4)$ & $19(30.2)$ & 0.005 \\
\hline Smoker & $25(17.9)$ & $10(15.9)$ & 0.73 \\
\hline$T 4$ tumour & $13(9.3)$ & $8(12.7)$ & 0.46 \\
\hline \multicolumn{4}{|l|}{ Surgeon } \\
\hline $1^{\mathrm{b}}$ & 39 (27.9) & $8(12.7)$ & \multirow{5}{*}{0.001} \\
\hline 2 & $44(31.4)$ & $8(12.7)$ & \\
\hline 3 & $21(15)$ & $41(65)$ & \\
\hline 4 & $19(13.6)$ & $3(4.8)$ & \\
\hline 5 & $17(12.1)$ & $3(4.8)$ & \\
\hline Mean BMI $\left(\mathrm{kg} / \mathrm{m}^{2}\right)^{\mathrm{c}}$ & 26.3 & 26.7 & 0.62 \\
\hline Tumour height, mean $(\mathrm{mm})^{\mathrm{c}}$ & 68.0 & 77.3 & 0.12 \\
\hline \multicolumn{4}{|l|}{ Tumour level } \\
\hline Upper rectum & $41(29.5)$ & $35(54.7)$ & \multirow[t]{3}{*}{0.003} \\
\hline Mid-rectum & $50(36.0)$ & $16(25.0)$ & \\
\hline Low rectum & $48(34.5)$ & $13(20.3)$ & \\
\hline
\end{tabular}

${ }^{a} X^{2}$ test analysis unless otherwise stated

${ }^{\mathrm{b}}$ Surgeon 1 is the combined operations of surgeons with less than 20 procedures

${ }^{\mathrm{c}} T$ test

Patients managed with a defunctioning stoma had a mean primary length of hospital stay of 13 days compared to 6.9 days $(p=0.005)$.

Table 6 shows univariate analysis of potential patient and surgical factors associated with post-operative complications, and those with $p$ value $<0.2$ were subjected to multiple logistic regression to identify independent associations (Table 7). Only the presence of a defunctioning stoma and ASA score $\geq 3$ were independently associated with post-operative complications. 
Table 3 Multiple logistic regression analysis of factors associated with creation of a defunctioning stoma

\begin{tabular}{lllc}
\hline & Odds ratio & $95 \%$ CI & $p$ value \\
\hline Open surgery & 1.74 & $0.42-7.39$ & 0.45 \\
Neoadjuvant radiotherapy & 2.12 & $0.79-5.66$ & 0.13 \\
Surgeon & & & \\
1 & 1.00 (reference) & & \\
2 & 1.03 & $0.23-4.58$ & 0.96 \\
3 & 0.13 & $0.05-0.38$ & $<0.001$ \\
4 & 1.51 & $0.35-6.63$ & 0.58 \\
5 & 1.72 & $0.38-7.84$ & 0.48 \\
Level of tumour & & & \\
Upper rectal & 1.00 (reference) & & \\
Mid-rectal & 1.58 & $0.60-4.21$ & 0.36 \\
Low rectal & 2.34 & $0.75-7.38$ & 0.15 \\
\hline
\end{tabular}

$C I$ confidence interval

Table 4 Comparison of patient and treatment characteristics according to tumour level

\begin{tabular}{llllc}
\hline & \multicolumn{2}{l}{ Level of rectal cancer } & $p$ value \\
\cline { 2 - 4 } & $\begin{array}{l}\text { Upper } \\
(n=76)\end{array}$ & $\begin{array}{l}\text { Middle } \\
(n=66)\end{array}$ & $\begin{array}{l}\text { Lower } \\
(n=61)\end{array}$ & \\
\hline Age, years $^{\mathrm{a}}$ & 68.6 & 66.8 & 65.0 & 0.20 \\
$\begin{array}{l}\text { Charlson score } \\
\geq 4\end{array}$ & $17(22.4)$ & $12(18.2)$ & $12(19.7)$ & 0.82 \\
$<4$ & $59(77.6)$ & $54(81.8)$ & $49(80.3)$ & \\
$\begin{array}{l}\left.\text { BMI (kg/m }{ }^{2}\right)^{\mathrm{a}} \\
\text { Neoadjuvant }\end{array}$ & 27.5 & 25.9 & 25.6 & 0.08 \\
$\quad$ radiotherapy & $5(5.5)$ & $38(41.8 \%)$ & $48(52.8)$ & $<0.001$ \\
$\begin{array}{l}\text { Surgical } \\
\text { technique }\end{array}$ & & & & \\
$\begin{array}{l}\text { Open } \\
\text { Laparoscopic }\end{array}$ & $47(61.9)$ & $36(54.6)$ & $43(70.5)$ & \\
\hline
\end{tabular}

Percentages in parenthesis unless otherwise stated

Comparisons using $X^{2}$ test unless otherwise stated

$O R$ odds ratio, $\mathrm{CI}$ confidence interval

${ }^{\mathrm{a}} T$ test, means

\section{Patients requiring reoperation}

Eleven patients with a defunctioning stoma required a reoperation as a result of complications, which included 7 patients requiring an unplanned abdominal reoperation as follows: 2 patients required an urgent early reversal of stoma, 2 patients required laparotomy and revision of their stoma for ischaemic necrosis, 2 patients required laparotomy for lavage (one for an intraabdominal collection and another for an anastomotic leak) and one required laparotomy and adhesiolysis to relieve small bowel obstruction. The other 4 patients with defunctioning stomas requiring reoperations all received examination under anaesthesia, lavage \pm transrectal drainage for anastomotic leak $(n=3)$ or suspected haemorrhage from the anastomosis $(n=1)$. By contrast, 11 patients who did not receive an initial defunctioning stoma required an abdominal operation as a result of post-operative complications. Most abdominal operations in this group were to treat intraabdominal sepsis secondary to anastomotic leak, with 9 patients having a stoma formed at reoperation. Only one patient required the anastomosis to be taken down and an end colostomy formed. Five of the other 8 patients who subsequently received a stoma had the reoperation performed laparoscopically without the need to resort to laparotomy.

\section{Stoma-related complications}

Thirty-seven stoma-related complications occurred in 27 (19.3\%) patients within 90 days. Four patients required urgent or unplanned reoperations as a result of stoma-related complications. The most common stoma-related complication was high output $(n=18)$, which resulted in acute kidney injury in 6 patients. Three patients had bowel obstruction which on radiological studies appeared directly related to the stoma, and 6 others in this group developed bowel obstruction at a site other than the stoma (distinguished from ileus by radiological features on CT scan).

Seventy-eight patients $(55.7 \%)$ who initially received a defunctioning stoma still had the stoma 1 year later. There were many and varied reasons for this including anastomotic stricture requiring treatment $(n=11)$, medically unwell or too frail for further surgery $(n=11)$, post-operative complications after original surgery $(n=10)$, local or distant recurrence detected $(n=14)$, complications with adjuvant chemotherapy delaying stoma closure $(n=3)$, suspected abnormalities detected on radiological imaging requiring further investigations $(n=4)$, other miscellaneous $(n=5)$ and several due to long waiting list times $(n=20)$. Thirty-six patients $(25.7 \%)$ remained with a stoma at the time of last follow-up (mean follow-up 34.4 months). Six (9.5\%) patients who did not initially receive a defunctioning stoma remained with a stoma at last follow-up.

\section{Discussion}

Several studies, including multiple meta-analyses, suggest that the use of a defunctioning stoma in anterior resection reduces the risk or diminishes the consequences of an anastomotic leak [4-7, 18, 19, 25-30]. However, the magnitude of this benefit is uncertain and there are no accurate means of identifying which patients will benefit from a defunctioning stoma. It is clear that, in 
Table 5 Comparison of 90-day post-operative outcomes between patients managed with and without defunctioning stomas

\begin{tabular}{|c|c|c|c|c|}
\hline \multirow[t]{2}{*}{ Outcome } & \multicolumn{2}{|c|}{ Defunctioning stoma $n(\%)$} & \multirow[t]{2}{*}{ OR $(95 \% \mathrm{CI})$} & \multirow[t]{2}{*}{$p$ value } \\
\hline & Yes & No & & \\
\hline Overall complications & $80(57.1)$ & $22(34.9)$ & $2.48(1.34-4.60)$ & 0.003 \\
\hline Anastomotic leak & 19 (13.6) & $9(14.3)$ & $0.94(0.40-2.22)$ & 0.89 \\
\hline Abdominal sepsis & 26 (18.6) & $13(20.7)$ & $0.87(0.42-1.85)$ & 0.73 \\
\hline Ileus & $18(12.9)$ & $1(1.6)$ & $9.37(1.22-71.8)$ & 0.009 \\
\hline Bowel obstruction & $9(6.4)$ & $0(0)$ & Undefined & $0.06^{\mathrm{a}}$ \\
\hline \multicolumn{5}{|l|}{ Complications according to severity } \\
\hline Clavien-Dindo 1 & $14(10.0)$ & $1(1.6)$ & & $<0.001$ \\
\hline Clavien-Dindo 2 & $45(32.1)$ & $7(11.1)$ & & \\
\hline Clavien-Dindo $3 \mathrm{a}$ & $5(3.6)$ & $0(0)$ & & \\
\hline Clavien-Dindo 3b & $9(6.4)$ & $11(17.5)$ & & \\
\hline Clavien-Dindo $4 \mathrm{a}$ & $4(2.9)$ & $2(3.2)$ & & \\
\hline Clavien-Dindo $4 \mathrm{~b}$ & $2(1.4)$ & $0(0)$ & & \\
\hline Clavien-Dindo 5 & $1(0.7)$ & $1(1.6)$ & & \\
\hline Significant complications (Clavien-Dindo $\geq 2$ ) & $66(47.1)$ & $21(33.1)$ & $1.78(0.96-3.32)$ & 0.06 \\
\hline Multiple complications & $25(17.9)$ & $2(3.2)$ & $6.63(1.52-28.9)$ & 0.004 \\
\hline Reoperation & $11(7.9)$ & $13(20.6)$ & $0.33(0.14-0.78)$ & 0.009 \\
\hline Readmission & $27(19.6)$ & $14(22.2)$ & $0.85(0.41-1.76)$ & 0.66 \\
\hline Mortality & $1(0.71)$ & $1(1.59)$ & $0.45(0.03-7.25)$ & 0.56 \\
\hline Length of hospital stay in days ${ }^{\mathrm{a}}$ & $13.0(8)$ & $6.9(4)$ & & 0.005 \\
\hline Total length of hospital stay in days ${ }^{a}$ & $14.1(9)$ & $10.7(5)$ & & 0.15 \\
\hline
\end{tabular}

Percentages in parenthesis unless otherwise stated

Comparisons using $X^{2}$ test unless otherwise stated

Total length of hospital stay includes duration of stay for unplanned readmissions but not hospital stay associated with stoma reversal or subsequent complications

$O R$ odds ratio, CI confidence interval

${ }^{\mathrm{a}} T$ test, means

contemporary practice, the majority of patients undergoing anterior resection for rectal cancer receive an initial defunctioning stoma, making the practice almost routine in many centres [1-3]. Despite these high rates of defunctioning stoma use, there are very few studies comparing overall complication rates in patients who are managed with a defunctioning stoma to those without [8-10], and few of the RCTs or non-randomised studies examining the effect of defunctioning stomas on anastomotic leak report overall complications [18, 27, 29]. Evidence of the effect of forming a defunctioning stoma on overall short-term morbidity, which is currently lacking, may well influence a surgeon's decision to create a stoma during anterior resection.

We found that patients who have a defunctioning stoma created during anterior resection have an increase in overall complications of $22 \%$. Patients with a defunctioning stoma were more likely to suffer multiple complications, almost $20 \%$ experienced ileus or bowel obstruction and almost $20 \%$ experienced a stoma-related complication. The rates of anastomotic leak or abdominal sepsis in general were not significantly different in patients with and without a defunctioning stoma.

These results contrast with the only other published study including over 200 patients comparing complication rates in which Anderin et al. [8] reported a complication rate among patients with a defunctioning stoma of $53 \%$ compared to $43 \%$ in those without. However, this study reported 30-day post-operative complications. A significant number of adverse post-operative outcomes are missed when only considering 30-day outcomes compared to 90-day outcomes [31, 32] and it is possible that this partly accounts for the higher morbidity found in our study. It is also noteworthy that only $15 \%$ of patients received a defunctioning stoma in the initial period of that study compared to $91 \%$ during the latter period, and the rate of anastomotic leak did not differ between these two periods leading the authors to call into question such routine use of stomas.

In a smaller study, Ihnát et al. [33] found significantly higher overall morbidity in patients managed with a defunctioning stoma compared to those without (42.3 vs 
Table 6 Univariate analysis of patient and surgical factors and postoperative complications

\begin{tabular}{|c|c|c|c|}
\hline & $\begin{array}{l}\text { Post-operative } \\
\text { complication, } n(\%)\end{array}$ & OR $(95 \% \mathrm{CI})$ & $p$ value \\
\hline \multicolumn{4}{|l|}{$\begin{array}{l}\text { Defunctioning } \\
\text { stoma }\end{array}$} \\
\hline Yes & $80(57.1)$ & $2.48(1.34-4.60)$ & 0.003 \\
\hline No & $22(34.9)$ & & \\
\hline \multicolumn{4}{|l|}{$\begin{array}{l}\text { Surgical } \\
\text { technique }\end{array}$} \\
\hline Open & $38(49.4)$ & $0.94(0.54-1.66)$ & 0.84 \\
\hline Laparoscopic & $64(50.8)$ & & \\
\hline \multicolumn{4}{|l|}{ Surgeon } \\
\hline 1 & $24(51.1)$ & & 0.05 \\
\hline 2 & $23(44.2)$ & & \\
\hline 3 & $26(41.9)$ & & \\
\hline 4 & $17(77.3)$ & & \\
\hline 5 & $12(60.0)$ & & \\
\hline \multicolumn{4}{|l|}{ Level of tumour } \\
\hline Upper rectal & $31(40.8)$ & & 0.11 \\
\hline Mid-rectal & $37(56.1)$ & & \\
\hline Low rectal & $34(55.7)$ & & \\
\hline \multicolumn{4}{|l|}{$\begin{array}{l}\text { Neoadjuvant } \\
\text { radiotherapy }\end{array}$} \\
\hline Yes & $46(50.6)$ & $1.02(0.59-1.78)$ & 0.94 \\
\hline No & $56(50.0)$ & & \\
\hline \multicolumn{4}{|l|}{$\begin{array}{l}\text { Operation time } \\
\text { (mins) }\end{array}$} \\
\hline$<180$ & $36(47.4)$ & & 0.01 \\
\hline $180-239$ & $17(37.8)$ & & \\
\hline 240-299 & $11(42.3)$ & & \\
\hline$\geq 300$ & $38(67.9)$ & & \\
\hline \multicolumn{4}{|l|}{ ASA score $\geq 3$} \\
\hline Yes & 34 (59.7) & $1.70(0.91-3.16)$ & 0.09 \\
\hline No & $68(46.6)$ & & \\
\hline \multicolumn{4}{|l|}{$\begin{array}{l}\text { Charlson } \\
\quad \text { score } \geq 4\end{array}$} \\
\hline Yes & $24(58.5)$ & $1.52(0.76-3.04)$ & 0.23 \\
\hline No & $78(48.2)$ & & \\
\hline \multicolumn{4}{|l|}{ Smoking } \\
\hline Yes & $18(51.4)$ & $1.06(0.51-2.19)$ & 0.88 \\
\hline No & $84(50.0)$ & & \\
\hline \multicolumn{4}{|l|}{ Age } \\
\hline$>70$ years & $42(48.9)$ & $0.91(0.52-1.58)$ & 0.73 \\
\hline$<70$ years & $60(51.3)$ & & \\
\hline \multicolumn{4}{|l|}{ BMI } \\
\hline$\geq 30 \mathrm{~kg} / \mathrm{m}^{2}$ & $11(45.8)$ & $0.86(0.36-2.1)$ & 0.75 \\
\hline$<30 \mathrm{~kg} / \mathrm{m}^{2}$ & $50(49.5)$ & & \\
\hline
\end{tabular}

Percentages in parenthesis

$O R$ odds ratio, $C I$ confidence interval
Table 7 Multiple logistic regression analysis of factors associated with post-operative complications

\begin{tabular}{llll}
\hline & Odds ratio & $95 \%$ CI & $p$ value \\
\hline $\begin{array}{l}\text { Defunctioning stoma } \\
\text { Surgeon }\end{array}$ & 2.62 & $1.19-5.78$ & 0.02 \\
1 & & & \\
2 & 1.00 (reference) & & \\
3 & 0.73 & $0.24-2.24$ & 0.58 \\
4 & 1.30 & $0.47-3.57$ & 0.61 \\
5 & 2.53 & $0.75-8.56$ & 0.14 \\
Level of tumour & 0.99 & $0.30-3.19$ & 0.98 \\
Upper rectal & 1.00 (reference) & & \\
Mid-rectal & 1.85 & $0.86-3.98$ & 0.12 \\
Low rectal & 1.53 & $0.70-3.33$ & 0.29 \\
ASA $\geq 3$ & 2.39 & $1.15-4.98$ & 0.02 \\
Operation time (min) & & & \\
$<180$ & 1.00 (reference) & & \\
$180-239$ & 0.60 & $0.25-1.44$ & 0.25 \\
$240-299$ & 0.60 & $0.18-1.92$ & 0.38 \\
$\geq 300$ & 1.46 & $0.42-5.01$ & 0.55 \\
\hline
\end{tabular}

$23.3 \%$ ), although only laparoscopic anterior resection was considered. Gumbau et al. compared outcomes in a small group of patients and found no significant differences in overall complications, however this study may have lacked a sufficient sample size and appears to have included all anterior resections rather than selecting low anterior resections. Only 4 patients who had TME did not receive a defunctioning stoma.

The magnitude of any benefit of defunctioning stomas is hugely variable among studies, reflected in a systematic review and meta-analysis in which the pooled rate of anastomotic leak and reoperation in low anterior resection showed a benefit in favour of defunctioning stomas of less than $2 \%$ [34]. Given the possibility that a defunctioning stoma may only offer a relatively small absolute benefit, an increase in complications of $22 \%$ in patients with a defunctioning stoma should prompt surgeons to carefully consider the near routine use of stomas in anterior resection. Even the most generous interpretation of the literature would conclude that the majority of patients receiving defunctioning stomas will not derive any benefit, and therefore subjecting $80 \%$ of patients undergoing anterior resection to a defunctioning stoma, as is the case in many centres $[1-3,33]$, means subjecting many patients to this significantly increased risk of complications.

It is important to consider the consequences of more selective use of defunctioning stomas. Nine patients who did not have an initial defunctioning stoma went on to have a stoma created at a subsequent reoperation for a suspected anastomotic leak. One had a further resection and 
formation of an end colostomy as a result of extensive ischaemic necrosis. Two patients underwent laparotomy and formation of a defunctioning stoma. The remaining 6 patients had a laparoscopic procedure; in 2 patients no anastomotic leak was discovered but a defunctioning stoma was formed in any case. The other 4 patients had laparoscopic lavage and formation of a defunctioning stoma. Four patients had the stoma closed. Therefore $14 \%$ of patients who did not initially receive a defunctioning stoma subsequently had a stoma formed at reoperation and 9.5\% remain with what could be considered a permanent stoma compared to $26 \%$ of patients who received an initial "temporary" defunctioning stoma. This demonstrates that selective use of defunctioning stomas results in far fewer patients ultimately requiring a stoma, as well as far fewer patients remaining with what could be considered a permanent stoma after a mean follow-up of almost 3 years. This figure may initially seem surprising, but it reflects common practice and is similar to other published findings, including national figures $[35,36]$. We feel it is a very important and often overlooked consideration in deciding to form a defunctioning stoma, and one about which patients are very seldom informed.

Although a plethora of potential risk factors for anastomotic leak have been identified [37], none have definitively emerged to help surgeons decide which patients would benefit from a defunctioning stoma, leaving surgeons basing the decision on preconceived ideas of significant risk factors. For example, many surgeons consider neoadjuvant chemoradiotherapy to be a significant risk factor for anastomotic leak; however, there is strong evidence that this is not the case $[38,39]$. Also, the decision to create a stoma could be related to a surgeon's age or personality with one study showing that younger surgeons and those with a lower propensity for risk-taking were more likely to decide to create a defunctioning stoma [40]. Routinely creating defunctioning stomas based on unproven risk factors for anastomotic leak or a surgeon's personality traits might lead to patients, many elderly with significant comorbidities, being subjected to a significant increased risk of complications or remaining with a permanent stoma. Forming a stoma is a significant additional procedure which unsurprisingly could result in additional complications although some findings in this study, such as the much higher risk of developing ileus after stoma formation, are somewhat less self-evident. We believe the additional manipulation and handling of the small bowel required to form a stoma could lead to ileus, especially during a laparoscopic procedure during which very minimal manipulation of the small bowel is performed.

It is also important to address concerns about higher reoperation rates in patients who do not receive a defunctioning stoma. Although a higher portion of these patients undergoes reoperations, this study shows that in many cases these can be completed laparoscopically thus minimising the impact.

\section{Limitations}

There are several limitations to the current study. This was not a randomised controlled study and is therefore subject to selection bias. It is likely that many patients with a defunctioning stoma were considered to be at higher risk of anastomotic leak by the operating surgeon and that the results of this study reflect good patient selection by the operating surgeon, particularly by those surgeons who tend to fashion fewer defunctioning stomas.

A higher proportion of patients receiving a defunctioning stoma in this study had been treated with neoadjuvant chemotherapy or radiotherapy but the groups were well matched in all other respects. It is possible that other risk factors which were not recorded in this study influenced the surgeon's decision to fashion a defunctioning stoma and these may have predisposed patients to developing postoperative complications. However, there were no differences between groups in mean age, sex, smoking status, BMI, T4 tumours, ASA or Charlson comorbidity scores and it is therefore difficult to speculate on what other risk factors for complications may have been present. We also included as homogeneous a patient population as possible by using objective methods in deciding which patients had a low anterior resection and should be included in the study. The definition varies widely among studies on defunctioning stomas and the majority do not specify the method of measurement. We feel that strategies such as assessment on digital rectal examination or colonoscopy are inaccurate in assessing the tumour level, and rigid sigmoidoscopy was not consistently performed on every patient in this study and is usually done with an unprepared rectum in which tumours were sometimes missed, and was therefore neither as widely available nor objectively reproducible as MRI or the histopathological analysis for this study.

A higher proportion of patients who had laparoscopic surgery were managed without a defunctioning stoma compared to those who had open surgery. However, open surgery was eliminated as a significant factor associated with the decision to create a defunctioning stoma on multiple regression analysis. The difference in the proportion of patients who received a defunctioning stoma was more likely driven by the preference for a more selective use of defunctioning stomas by one of the laparoscopic surgeons compared to those practising mostly open surgery. On multivariate analysis, the operating surgeon, tumour level, length of operation and neoadjuvant radiotherapy were not independently associated with complications. Only the 
presence of a defunctioning stoma and ASA score $\geq 3$, and not open surgery, were associated with a significantly increased post-operative complication rate, in keeping with evidence that open surgery is not associated with more complications than laparoscopic surgery in rectal resection, with 2 recent well-conducted randomised controlled trials in rectal cancer resection showing complication rates for open and laparoscopic surgery [41, 42].

$45 \%$ of patients in this study received neoadjuvant radiotherapy, which may be lower than similar cohorts in the USA but is, however, very similar to rates of neoadjuvant radiotherapy to rectal cancer patients in the UK, much of Europe as well as Australia and is therefore representative of other rectal cancer patient cohorts undergoing surgery $[1,41,43]$.

\section{Conclusion}

This study shows that patients selected to have a defunctioning stoma at anterior resection have a significantly increased risk of overall complications, are more likely to suffer multiple complications and have a longer primary hospital stay. Almost 1 in 5 patients suffered a stoma-related complication and $26 \%$ remained with a stoma at last follow-up compared to $9.5 \%$ of other patients. These findings support the more selective use of stomas in anterior resection.

Acknowledgements The authors gratefully acknowledge the assistance of Mrs Diane Onyango in completing this study.

\begin{abstract}
Author contributions AE: Conception and design of study; acquisition, analysis and interpretation of data; drafted the manuscript; final approval, EC: Conception and design of study; acquisition and interpretation of data; critical revision of manuscript; final approval, CL: Conception and design of study; acquisition and interpretation of data; critical revision of manuscript; final approval, AM: Conception and design of study; interpretation of data; critical revision of manuscript; final approval, AH: Conception and design of study; interpretation of data; critical revision of manuscript; final approval, JE: Conception and design of study; interpretation of data; critical revision of manuscript; final approval.
\end{abstract}

\section{Compliance with ethical standards}

Conflict of interest The authors of this manuscript do not have any financial disclosures or competing interests to declare.

Open Access This article is distributed under the terms of the Creative Commons Attribution 4.0 International License (http://crea tivecommons.org/licenses/by/4.0/), which permits unrestricted use, distribution, and reproduction in any medium, provided you give appropriate credit to the original author(s) and the source, provide a link to the Creative Commons license, and indicate if changes were made.

\section{References}

1. Healthcare Quality Improvement Partnership 2017. National Bowel Cancer Audit: Annual Report 2017. https://www.hqip. org.uk/resources/national-bowel-cancer-audit-annual-report-2017. Accessed 6 Apr 2018

2. Snijders HS, van den Broek CBM, Wouters MWJM et al (2013) An increasing use of defunctioning stomas after low anterior resection for rectal cancer. Is this the way to go? Eur J Surg Oncol 39:715-720. https://doi.org/10.1016/j.ejso.2013.03.025

3. Rutegård M, Boström $\mathrm{P}$, Haapamäki $\mathrm{M}$ et al (2016) Current use of diverting stoma in anterior resection for cancer: populationbased cohort study of total and partial mesorectal excision. Int $\mathbf{J}$ Colorectal Dis 31:579-585. https://doi.org/10.1007/s00384-0152465-6

4. Montedori A, Cirocchi R, Farinella E et al (2010) Covering ileoor colostomy in anterior resection for rectal carcinoma. Cochrane Database Syst Rev. https://doi.org/10.1002/14651858.cd006878. pub2

5. Gu W, Wu S (2015) Meta-analysis of defunctioning stoma in low anterior resection with total mesorectal excision for rectal cancer: evidence based on thirteen studies. World J Surg Oncol 13:9. https://doi.org/10.1186/s12957-014-0417-1

6. Hüser N, Michalski CW, Erkan M et al (2008) Systematic review and meta-analysis of the role of defunctioning stoma in low rectal cancer surgery. Ann Surg 248:52-60. https://doi.org/10.1097/ SLA.0b013e318176bf65

7. Tan WS, Tang CL, Shi L, Eu KW (2009) Meta-analysis of defunctioning stomas in low anterior resection for rectal cancer. Br J Surg 96:462-472. https://doi.org/10.1002/bjs.6594

8. Anderin K, Gustafsson UO, Thorell A, Nygren J (2015) The effect of diverting stoma on postoperative morbidity after low anterior resection for rectal cancer in patients treated within an ERAS program. Eur J Surg Oncol 41:724-730. https://doi.org/10. 1016/j.ejso.2015.03.234

9. Ihnát P, Guňková P, Peteja $\mathrm{M}$ et al (2016) Diverting ileostomy in laparoscopic rectal cancer surgery: high price of protection. Surg Endosc 30:4809-4816. https://doi.org/10.1007/s00464-016-48113

10. Gumbau V, García-Armengol J, Salvador-Martínez A et al (2015) Impact of a diverting stoma in an enhanced recovery programme for rectal cancer. Cir Esp 93:18-22. https://doi.org/10.1016/j.cir esp.2014.03.016

11. Åkesson O, Syk I, Lindmark G, Buchwald P (2012) Morbidity related to defunctioning loop ileostomy in low anterior resection. Int J Colorectal Dis 27:1619-1623. https://doi.org/10.1007/ s00384-012-1490-y

12. Giannakopoulos GF, Veenhof AA, van der Peet DL et al (2009) Morbidity and complications of protective loop ileostomy. Colorectal Dis 11:609-612. https://doi.org/10.1111/j.1463-1318. 2008.01690.x

13. Mala T, Nesbakken A (2008) Morbidity related to the use of a protective stoma in anterior resection for rectal cancer. Colorectal Dis 10:785-788. https://doi.org/10.1111/j.1463-1318.2007.01456.x

14. Monson JRT, Weiser MR, Buie WD et al (2013) Practice parameters for the management of rectal cancer (revised). Dis Colon Rectum 56:535-550. https://doi.org/10.1097/DCR. 0b013e31828cb66c

15. Nygren J, Thacker J, Carli F et al (2013) Guidelines for perioperative care in elective rectal/pelvic surgery: Enhanced Recovery After Surgery (ERAS $\left({ }^{\circledR}\right)$ ) Society recommendations. World J Surg 37:285-305. https://doi.org/10.1007/s00268-012-1787-6

16. Lowry AC, Simmang CL, Boulos P et al (2001) Consensus statement of definitions for anorectal physiology and rectal cancer. Colorectal Dis 3:272-275 
17. Kenig J, Richter P (2013) Definition of the rectum and level of the peritoneal reflection-still a matter of debate? Wideochir Inne Tech Maloinwazyjne 8:183-186. https://doi.org/10.5114/wiitm. 2011.34205

18. Mrak K, Uranitsch S, Pedross F et al (2016) Diverting ileostomy versus no diversion after low anterior resection for rectal cancer: a prospective, randomized, multicenter trial. Surgery 159:1129-1139. https://doi.org/10.1016/j.surg.2015.11.006

19. Thoker M, Wani I, Parray FQ et al (2014) Role of diversion ileostomy in low rectal cancer: a randomized controlled trial. Int J Surg 12:945-951. https://doi.org/10.1016/j.ijsu.2014.07.012

20. Hanna MH, Vinci A, Pigazzi A (2015) Diverting ileostomy in colorectal surgery: when is it necessary? Langenbecks Arch Surg 400:145-152. https://doi.org/10.1007/s00423-015-1275-1

21. MERCURY Study Group (2006) Diagnostic accuracy of preoperative magnetic resonance imaging in predicting curative resection of rectal cancer: prospective observational study. BMJ 333:779. https://doi.org/10.1136/bmj.38937.646400.55

22. Nougaret S, Reinhold C, Mikhael HW et al (2013) The use of MR imaging in treatment planning for patients with rectal carcinoma: have you checked the "DISTANCE"? Radiology 268:330-344. https://doi.org/10.1148/radiol.13121361

23. Beets-Tan RGH, Lambregts DMJ, Maas M et al (2013) Magnetic resonance imaging for the clinical management of rectal cancer patients: recommendations from the 2012 European Society of Gastrointestinal and Abdominal Radiology (ESGAR) consensus meeting. Eur Radiol 23:2522-2531. https://doi.org/10.1007/ s00330-013-2864-4

24. Dindo D, Demartines N, Clavien P-A (2004) Classification of surgical complications: a new proposal with evaluation in a cohort of 6336 patients and results of a survey. Ann Surg 240:205-213

25. Chude GG, Rayate NV, Patris V et al (2008) Defunctioning loop ileostomy with low anterior resection for distal rectal cancer: should we make an ileostomy as a routine procedure? A prospective randomized study. Hepatogastroenterology 55: $1562-1567$

26. Matthiessen P, Hallböök O, Rutegård J et al (2007) Defunctioning stoma reduces symptomatic anastomotic leakage after low anterior resection of the rectum for cancer: a randomized multicenter trial. Ann Surg 246:207-214. https://doi.org/10.1097/SLA. 0b013e3180603024

27. Gastinger I, Marusch F, Steinert R et al (2005) Protective defunctioning stoma in low anterior resection for rectal carcinoma. Br J Surg 92:1137-1142. https://doi.org/10.1002/bjs.5045

28. Lin J-K, Yueh T-C, Chang S-C et al (2011) The influence of fecal diversion and anastomotic leakage on survival after resection of rectal cancer. J Gastrointest Surg 15:2251-2261. https://doi.org/ 10.1007/s11605-011-1721-5

29. Marusch F, Koch A, Schmidt U et al (2002) Value of a protective stoma in low anterior resections for rectal cancer. Dis Colon Rectum 45:1164-1171. https://doi.org/10.1097/01.DCR. 0000027040.59190 .12

30. Matthiessen P, Hallböök O, Andersson M et al (2004) Risk factors for anastomotic leakage after anterior resection of the rectum.
Colorectal Dis 6:462-469. https://doi.org/10.1111/j.1463-1318. 2004.00657.x

31. Byrne BE, Mamidanna R, Vincent CA, Faiz O (2013) Populationbased cohort study comparing 30- and 90-day institutional mortality rates after colorectal surgery. Br J Surg 100:1810-1817. https://doi.org/10.1002/bjs.9318

32. Langan RC, Huang C-C, Colton S et al (2015) Readmissions after major cancer surgery among older adults. Surgery 158:428-437. https://doi.org/10.1016/j.surg.2015.01.028

33. Ihnát $P$, Guňková $P$, Peteja $\mathrm{M}$ et al (2016) Diverting ileostomy in laparoscopic rectal cancer surgery: high price of protection. Surg Endosc. https://doi.org/10.1007/s00464-016-4811-3

34. Cong Z-J, Hu L-H, Zhong M, Chen L (2015) Diverting stoma with anterior resection for rectal cancer: does it reduce overall anastomotic leakage and leaks requiring laparotomy? Int $\mathrm{J}$ Clin Exp Med 8:13045-13055

35. Kuryba AJ, Scott NA, Hill J et al (2016) Determinants of stoma reversal in rectal cancer patients who had an anterior resection between 2009 and 2012 in the English National Health Service. Colorectal Dis 18:O199-O205. https://doi.org/10.1111/codi. 13339

36. Sier MF, van Gelder L, Ubbink DT et al (2015) Factors affecting timing of closure and non-reversal of temporary ileostomies. Int J Colorectal Dis 30:1185-1192. https://doi.org/10.1007/s00384015-2253-3

37. McDermott FD, Heeney A, Kelly ME et al (2015) Systematic review of preoperative, intraoperative and postoperative risk factors for colorectal anastomotic leaks. Br J Surg 102:462-479. https://doi.org/10.1002/bjs.9697

38. Hu M-H, Huang R-K, Zhao R-S et al (2016) Does neoadjuvant therapy increase the incidence of anastomotic leakage after anterior resection for mid and low rectal cancer? A systematic review and meta-analysis. Colorectal Dis. https://doi.org/10. $1111 /$ codi. 13424

39. Chang JS, Keum KC, Kim NK et al (2014) Preoperative chemoradiotherapy effects on anastomotic leakage after rectal cancer resection: a propensity score matching analysis. Ann Surg 259:516-521. https://doi.org/10.1097/SLA.0b013e31829068c5

40. MacDermid E, Young CJ, Young J, Solomon M (2014) Decisionmaking in rectal surgery. Colorectal Dis 16:203-208. https://doi. org/10.1111/codi.12487

41. Stevenson ARL, Solomon MJ, Lumley JW et al (2015) Effect of laparoscopic-assisted resection vs open resection on pathological outcomes in rectal cancer: the ALaCaRT randomized clinical trial. JAMA 314:1356-1363. https://doi.org/10.1001/jama.2015. 12009

42. Fleshman J, Branda M, Sargent DJ et al (2015) Effect of laparoscopic-assisted resection vs open resection of stage II or III rectal cancer on pathologic outcomes: the ACOSOG Z6051 randomized clinical trial. JAMA 314:1346-1355. https://doi.org/ 10.1001/jama.2015.10529

43. Kodeda K, Johansson R, Zar N et al (2015) Time trends, improvements and national auditing of rectal cancer management over an 18-year period. Colorectal Dis 17:O168-O179. https:// doi.org/10.1111/codi.13060 